\title{
Sarcoma de células dendríticas foliculares. Informe de un caso
}

Follicular dendritic cell sarcoma. Case report

\author{
Antonio S. Sosa-Luis' ${ }^{1}$, Claudia T. Gutiérrez-Quiroz', Francisco Espinosa-Zúñiga', \\ Daniel E. Meléndez-Mena ${ }^{1}$, Álvaro J. Montiel-Jarquín ${ }^{1 *}$ y Jorge Loría-Castellanos ${ }^{2}$ \\ ${ }^{1}$ Unidad Médica de Alta Especialidad, Hospital de Especialidades de Puebla, Instituto Mexicano del Seguro Social (IMSS); ${ }^{2}$ División de Proyectos \\ Especiales en Salud, IMSS. Puebla, Puebla, México
}

\section{Resumen}

Antecedentes: El sarcoma de células dendríticas foliculares es una enfermedad rara, caracterizada principalmente en sitios nodales como la cabeza, el cuello y la orofaringe, aunque puede ser extranodal, como en el bazo y el hígado. En la mayoría de los casos cursa asintomática, pero puede presentar síntomas generales, dolor abdominal o fiebre. La inmunohistoquímica es indispensable para llegar a un diagnóstico definitivo. Presentación del caso: Mujer de 40 años, con abultamiento submaxilar en el cuello, región frontoparietooccipital derecha, y sequedad de mucosa oral. Se manejó inicialmente como un síndrome de Sjögren, que fue descartado por el resultado histopatológico de la biopsia de glándula salival. Posteriormente se realizó biopsia de ganglio del cuello, que reportó sarcoma de células dendríticas foliculares con expresión inmunohistoquímica positiva para CD23 y negativa para CD21 y ACL. Se manejó con samario y tuvo una sobrevida de 3 meses desde el diagnóstico. Conclusiones: el sarcoma de células dendríticas foliculares es raro y la sobrevida es corta.

Palabras clave: Sarcoma. Células dendríticas. Inmunohistoquímica. Reporte de caso.

\begin{abstract}
Background: Follicular dendritic cell sarcoma is a rare pathology, it occurs mainly in nodal sites such as head, neck, oropharynx, although extranodal presentation such as spleen and liver may occur. In most cases it is asymptomatic but may present general symptoms, abdominal pain or fever. Immunohistochemistry is essential to make a definitive diagnosis. Case presentation: Forty year-old woman, with submaxillary lesion, in the neck, right fronto-parieto-occipital region with dry oral mucosa. It was initially managed as a Sjögren's syndrome ruled out by the histopathological result of salivary gland biopsy. Subsequently, a neck ganglion biopsy was performed that reported follicular dendritic cell sarcoma, with positive immunohistochemical expression for CD23 and negative for CD21 and LCA. It was managed with samarium with a survival of 3 months from the time of its diagnosis. Conclusions: Follicular dendritic cell sarcoma is rare and its global survival is short.
\end{abstract}

Key words: Sarcoma. Dendritic cells. Immunohistochemistry. Case report.

\footnotetext{
Correspondencia:

*Álvaro J. Montiel-Jarquín

2 norte 2004

Col. Centro

Fecha de recepción: 10-02-2020

C.P. 72000, Puebla, Pue., México

E-mail: dralmoja@ hotmail.com; Alvaro.montielj@imss.gob.mx

Fecha de aceptación: 20-01-2021

DOI: $10.24875 / C I R U .20000083$

0009-7411/@ 2021 Academia Mexicana de Cirugía. Publicado por Permanyer. Este es un artículo open access bajo la licencia CC BY-NC-ND (http://creativecommons.org/licenses/by-nc-nd/4.0/).
} 


\section{Introducción}

El sarcoma de células dendríticas foliculares (SCDF) es una neoplasia rara caracterizada por una diferenciación de las células dendríticas foliculares. Fue descrito por Monda, et al. en $1986^{1}$ y a la fecha se han reportado alrededor de 400 casos en la literatura mun$\mathrm{dial}^{2}$. Puede presentarse en el cuello, el mediastino, el bazo, el hígado y otros sitios, como la orofaringe.

La sintomatología depende de la localización de la tumoración; cuando es en el cuello puede ser asintomático, aunque algunos pacientes cursan con dolor abdominal o con manifestaciones sistémicas como fiebre, fatiga y diaforesis nocturna ${ }^{2,3,4,5}$. La evolución es variable. Actualmente no existe una estrategia bien establecida de tratamiento y su pronóstico es malo para la vida a plazo corto. El objetivo de este trabajo es presentar el caso clínico de una mujer con SCDF en el cuello, su evolución y su tratamiento.

\section{Caso clínico}

Mujer de 40 años que inició su padecimiento 6 meses antes, cuando notó un abultamiento submaxilar, en el cuello, región frontoparietooccipital derecha, con sequedad de la mucosa oral. Se manejó como un síndrome de Sjögren y se tomó biopsia de glándula salival, con reporte histopatológico sin criterios diagnósticos para este. Posteriormente, la paciente fue sometida a protocolo diagnóstico, con reporte de biometría hemática con depleción de las tres series: hemoglobina 11.6, plaquetas 19,000 , leucocitos 1300 , elevación de creatinina $(2.85 \mathrm{mg} / \mathrm{dl})$ y lactato deshidrogenasa $713 \mathrm{U} / \mathrm{l}$; pruebas de coagulación y pruebas de funcionamiento hepático normales. La tomografía computada de cabeza y cuello reportó una masa lateral del cuello de origen por determinar, sin poder descartar un proceso neoplásico, adenopatía en nivel II del lado izquierdo del cuello y en niveles II, III y IV del lado derecho (Fig. 1). El gammagrama óseo mostró lesiones líticas frontoparietales, sacroilíacas, femorales e isquiáticas bilaterales (Fig. 2).

Por la alteración en la biometría hemática y la etapa clínica avanzada, la paciente no fue considerada candidata para cirugía, por lo que se sometió únicamente a biopsia de la zona de abultamiento del cuello.

El reporte histopatológico fue SCDF (Fig. 3) y la inmunohistoquímica mostró expresión negativa para CD21, positiva para CD23 y negativa para antígeno común leucocitario (ACL) (Figs. 4 a 6).

El tratamiento establecido fue con samario a dosis de $3.4 \mathrm{mR} / \mathrm{h}$. A la paciente se le programaron sesiones

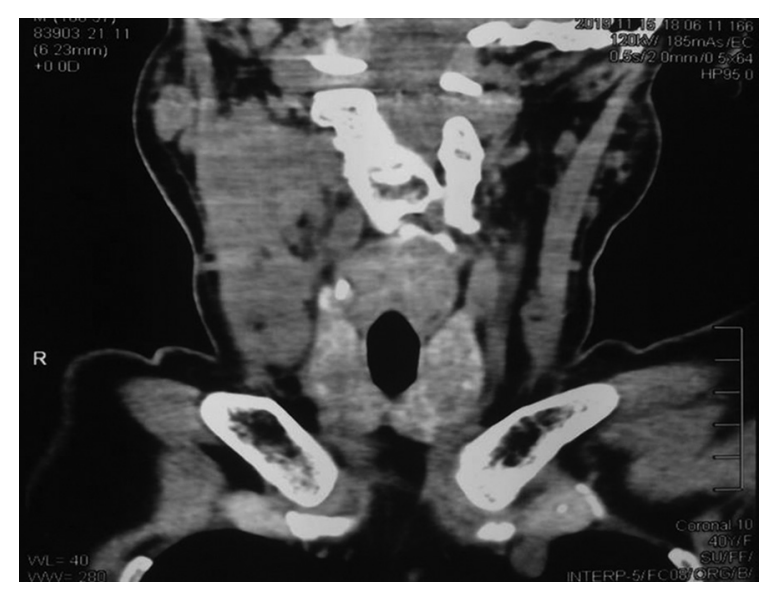

Figura 1. Tomografía computarizada: lesión lateral del cuello de origen por determinar, adenopatía en nivel Il del lado izquierdo del cuello y en niveles II, III y IV del lado derecho.

de radioterapia, las cuales no fueron concluidas porque presentó mal estado general, fatiga, astenia y adinamia, por lo que ameritó internamiento. Durante este internamiento se encontró anemia, plaquetopenia y leucocitopenia. Se le transfundieron hemoderivados y falleció 8 días después. La sobrevida de esta paciente fue de 3 meses desde el diagnóstico hasta el fallecimiento.

\section{Discusión}

EI SCDF es una proliferación neoplásica que implica la fusión de células ovoides con morfología y características fenotípicas similares a las de las células dendríticas foliculares normales. La Organización Mundial de la Salud la clasifica como una neoplasia de células histiocíticas y dendríticas ${ }^{3}$. Las células dendríticas son células no mieloides, no fagocíticas, de la inmunidad innata, que se encuentran principalmente en centros germinales y secundariamente en los órganos linfoides, y que se caracterizan por expresar CD21, CD35, R4/23 y KiM4e en su superficie ${ }^{3}$. EI SCDF puede ocurrir en los nodos linfoides y en sitios extranodales, como la cavidad oral, la nasofaringe, el tracto gastrointestinal, el hígado, el páncreas y el bazo ${ }^{5}$. Pang, et al. ${ }^{2}$, en una revisión de MEDLINE, publicaron dos casos de SCDF en hombres y reportaron 97 casos más en un período de 46 años (1978 a 2014), con presentación del $40 \%$ de los casos en los nodos linfoides, el $24 \%$ en la orofaringe y el $10 \%$ en los tejidos blandos del cuello. Las menores edades (30.1 \pm 16.5 años) de presentación fueron en pacientes con lesiones en los tejidos blandos del cuello, y las edades mayores ( $61.5 \pm 17.0$ años) en tiroides con un ligero predominio de presentación en 


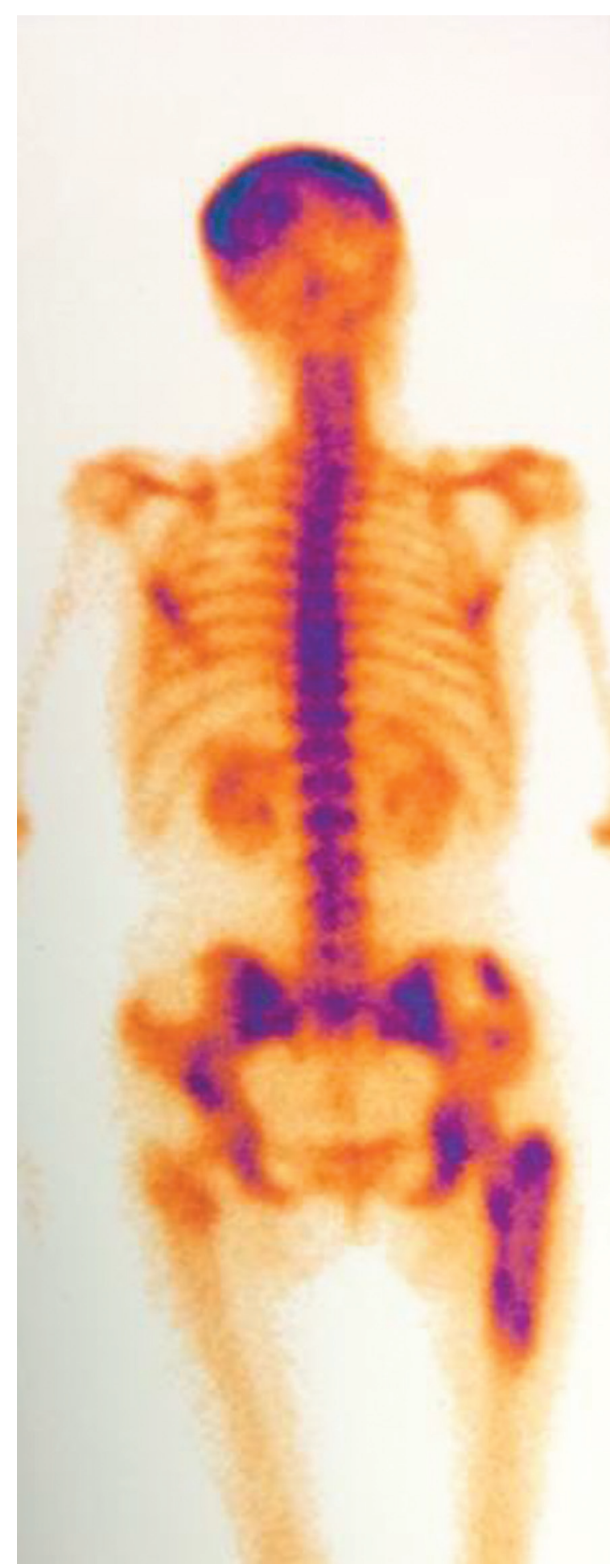

Figura 2. Gammagrama óseo: se observa un incremento de la actividad osteoblástica en el hueso frontal, los parietales, las articulaciones sacroiliacas, el isquion bilateral y el fémur.

los hombres (53\%) y un diámetro medio del tumor de $4.5 \mathrm{~cm}$. Otro estudio reporta 14 casos de SCDF durante los años 1995 a 2005, en el Anderson Cancer

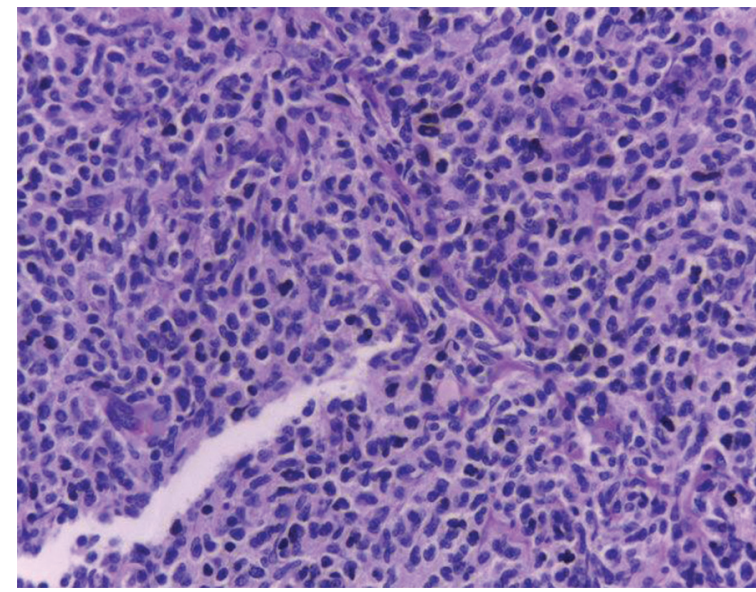

Figura 3. Tinción de hematoxilina y eosina ( $\times$ 40): se observan células de aspecto histiocítico, con nucleolo aparente y algunas de ellas con hendidura.

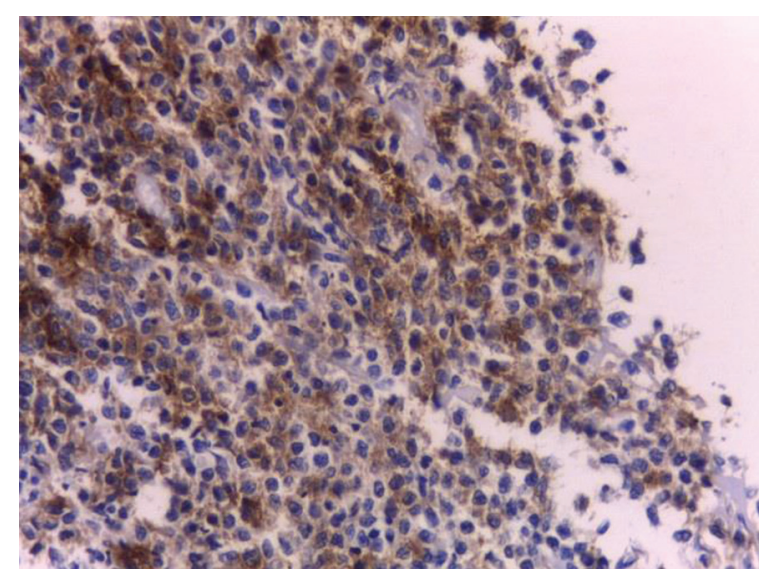

Figura 4. Inmunohistoquímica: expresión negativa para CD21.

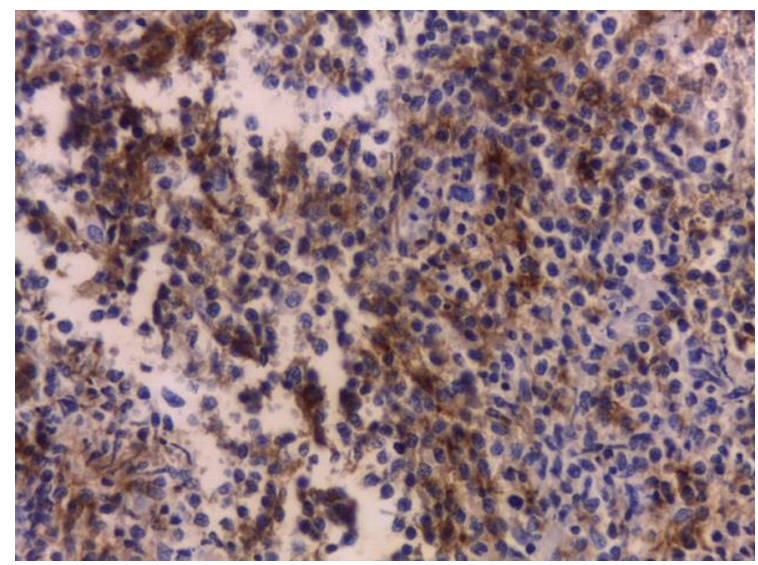

Figura 5. Inmunohistoquímica: expresión positiva para CD23.

Center, de los cuales el $21.42 \%$ presentaron linfadenopatía cervical, el 35.71\% linfadenopatía abdominal, el $21.42 \%$ tumoración mediastinal, el $14.28 \%$ 


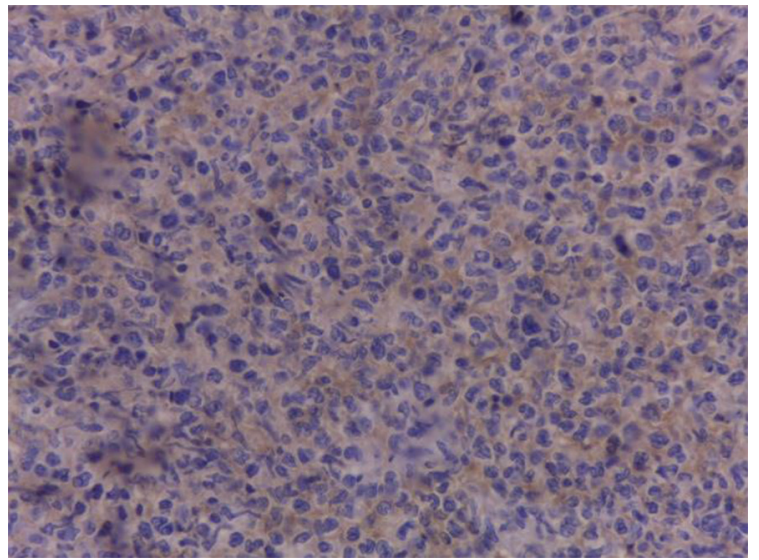

Figura 6. Inmunohistoquímica: expresión negativa para ACL.

enfermedad nasofaríngea y el $7.14 \%$ derrame pleural ${ }^{6}$. Generalmente los pacientes cursan asintomáticos y el único signo clínico puede ser una linfadenopatía cervical indolora y de crecimiento lento ${ }^{3}$. Se relacionan con síndromes paraneoplásicos, como pénfigo, miastenia grave y enfermedad de Castleman ${ }^{2,3}$. Existen marcadores de inmunohistoquímica que apoyan el diagnóstico, pero no son específicos. Algunos, como CD21, CD23 y CD35, son expresados frecuentemente en los SCDF, y existen otros marcadores, como CD68, vimentina y S100, que pueden estar expresados, pero que son más comunes en patologías como los sarcomas pleomórficos indiferenciados, la histiocitosis de células de Langerhans y los schwannomas, respectivamente ${ }^{1,6}$.

Los diagnósticos diferenciales para el SCDF incluyen el sarcoma de células dendríticas interdigitantes, los timomas, los carcinomas de células fusiformes, las metástasis de carcinoma indiferenciado, el melanoma maligno y los tumores gastrointestinales de células estromales (GIST) ${ }^{3}$.

La resección quirúrgica se puede llevar a cabo cuando la etapa clínica y las condiciones del paciente lo permiten. El tratamiento combinado con cirugía, radioterapia y quimioterapia parece ser la mejor opción, con una sobrevida de hasta 8 años ${ }^{6,7}$.

El SCDF tiene un curso clínico variable y actualmente no existe una estrategia de tratamiento uniforme. Su pronóstico es malo, con una sobrevida corta, la cual depende del estadio clínico en que se detecta la enfermedad. La recurrencia local es común (40-50\% de los casos reportados) y las metástasis en los tumores de ganglios linfáticos se presentan en el $10 \%$ de los pacientes aproximadamente, en comparación con los tumores extranodales, que tienen un potencial metastásico mayor $(20 \%)^{2,3}$.
Es importante destacar la utilidad de las técnicas de inmunohistoquímica en el estudio diferencial de este tipo de lesiones, por las altas sensibilidad y especificidad de los anticuerpos CD21, CD35 y CD23, como pudieron comprobar Jorge-Buys, et al. ${ }^{7}$ en su serie de cinco casos.

El caso presentado, diagnosticado en etapa clínica IV, presentó una gran morbilidad y una supervivencia corta (3 meses), lo cual concuerda con la literatura mundial.

\section{Financiamiento}

Este protocolo no requirió financiamiento externo.

\section{Conflicto de intereses}

Los autores declaran no tener conflicto de intereses.

\section{Responsabilidades éticas}

Protección de personas y animales. Los autores declaran que los procedimientos seguidos se conformaron a las normas éticas del comité de experimentación humana responsable y de acuerdo con la Asociación Médica Mundial y la Declaración de Helsinki.

Confidencialidad de los datos. Los autores declaran que han seguido los protocolos de su centro de trabajo sobre la publicación de datos de pacientes.

Derecho a la privacidad y consentimiento informado. Los autores han obtenido el consentimiento informado de los pacientes y/o sujetos referidos en el artículo. Este documento obra en poder del autor de correspondencia.

\section{Bibliografía}

1. Monda L, Warnke R, Rosai J. A primary lymph node malignancy with features suggestive of dendritic reticulum cell differentiation. A report of 4 cases. Am J Pathol. 1986;122:562-72.

2. Chen T, Gopal P. Follicular dendritic cell sarcoma. Arch Pathol Lab Med. 2017;141:596-9.

3. Pang J, Mydlarz WK, Gooi Z, Waters KM, Bishop J, Sciubba JJ, et al. Follicular dendritic cell sarcoma of the head and neck: case report, literature review, and pooled analysis of 97 cases. Head Neck. 2016;38(Suppl 1):E2241-9.

4. Wu A, Pullarkat S. Follicular dendritic cell sarcoma. Arch Pathol Lab Med. 2016;140:186-90.

5. An P, Li Y, Zhao J. Follicular dendritic cell sarcoma of the parotid gland: a case report. Oral Oncol. 2020;102:104515.

6. Soriano AO, Thompson MA, Admirand JH, Fayad LE, Rodriguez AM, Romaguera JE, et al. Follicular dendritic cell sarcoma: a report of 14 cases and a review of the literature. Am J Hematol. 2007;82:725-8.

7. Jorge-Buys DL, Lastra-Camacho G, Campos-Martínez J, Romero-Guadarrama M, Ortiz-Hidalgo C. Sarcoma de células dendríticas foliculares de localización ganglionar y extraganglionar. Estudio clinicopatológico e inmunohistoquímico de cinco casos. Cir Cir. 2008;76:145-52. 